\title{
TRANSCRIPTS AND ACCESSIBILITY: STUDENT VIEWS FROM USING WEBINARS IN BUILT ENVIRONMENT EDUCATION
}

Tharindu R. Liyanagunawardena [tharindu@cem.ac.uk], The College of Estate Management, United Kingdom

\begin{abstract}
Transcripts and captions make videos more accessible to everyone. However, the time and resources required for manual transcription are a known barrier in creating accessible videos. This paper presents a small study where students (283) and tutors (27) reported their views on automatic transcriptions for recorded webinar videos. Despite not having perfect transcription accuracy, many students who have used the automatic transcripts found them to be useful. Students were also asked how they used transcripts and this included: to find specific information in a video, as a learning aid, as an accessibility aid, to compensate for the speaker's accent and pace, to study on the go, to compensate for poor audio and/or connectivity and as an aid for non-native English speakers.
\end{abstract}

\section{Abstract in German}

Transkripte und Untertitel machen Videos für alle zugänglicher. Allerdings stellen die benötigten Ressourcen für manuelle Transkription ein bekanntes Hindernis für die Herstellung barrierefreier Videos dar. Dieser Aufsatz stellt eine Untersuchung vor, für die Studierende (283) und Lehrende (27) zu ihrer Meinung bezüglich automatisch erstellter Transkription für aufgezeichnete WebinarVideos befragt wurden. Obwohl die Transkription nicht hundertprozentig korrekt ausfällt, finden viele Studierende, die von ihnen benutzten automatisch erstellten Transkripte hilfreich. Studierende benutzten die Transkriptionen auf unterschiedliche Weise, beispielsweise um spezifische Informationen im Video zu finden, als Lernhilfe, als Hilfsmittel für Barrierefreiheit, um den Akzent des Sprechers oder das Sprechtempo zu kompensieren, um schlechte Audioqualität und/oder eine schlechte Verbindung auszugleichen, und als Verständnishilfe im Fall von NichtMuttersprachlern.

\section{Abstract in French}

Les transcriptions et les sous-titres rendent les vidéos plus accessibles pour tous. Mais les ressources nécessitées pour les transcriptions manuelles sont une véritable barrière pour créer les vidéos accessibles. Cet article présent une petite étude où les étudiants (dont 283) et les professeurs (dont 27) rapportent leurs opinions vers la transcription automatisée pour les vidéos de webinaires enregistrés. Malgré moins de $100 \%$ de précision, beaucoup d'étudiants qui ont utilisé les transcriptions automatisées les ont trouvés utiles. Les étudiants ont utilisé les transcriptions dans plusieurs façons : pour trouver les informations spécifiques dans une vidéo ; comme un outil d'apprentissage ; un outil de l'accessibilité ; pour compenser un accent ou la vitesse de la personne 
qui parle ; pour étudier à la volée ; pour compenser la mauvaise qualité d'audio ou mauvaise connexion ; comme un outil pour ceux que l'Anglais n'est pas la langue maternelle.

Keywords: Accessibility, captioning, automatic transcription, automatic transcription software

\section{Background}

The use of video in higher education has increased over the years and it has become an indispensable medium for distance education delivery with many Massive Open Online Courses (MOOCs) heavily relying on instructional videos. Reporting on the state of video in education in its sixth annual report, Kaltura, a leading video platform, states that "video is increasingly important to students both as part of educational experience and preparation for the modern workplace" (Kaltura, 2019). They report that $82 \%$ of over 1,400 international respondents (educational professionals, staff and students), surveyed for its sixth annual survey, saw an increase in expectation from students of how much video should be part of their learning experience. According to the Association for Learning Technology (ALT) annual survey for 2018, lecture capture tools had the biggest gain in importance for current practice (Association for Learning Technology, 2019) indicating the importance attached by higher education providers to offering recorded video lectures to students.

\section{Accessibility of Video}

This increasing use of video in higher education also comes with its challenges, especially for students with disabilities who may require alternative formats to access video content. The ALT survey showed that the percentage of respondents rating "Assistive Technology" as important/very important increased from 33\% in 2017 to $40 \%$ in 2018. This could be, at least in part, due to the introduction of the UK's new accessibility regulations, "The Public Sector Bodies (Websites and Mobile Applications) Accessibility Regulations", in September 2018. However, according to Kaltura (2019) only $27 \%$ of institutions routinely captioned all videos.

Video captioning can be costly depending on the turnaround time and the accuracy required. For example, the author's institution was charged an average rate of $£ 1.30$ per minute by a professional transcription service (subjected to a minimum fee and additional cost for more than one speaker) (Liyanagunawardena, 2019) while another institution indicated it was charged \$2.75 (about £2.19) per minute by a transcription service integrated into the lecture capture service (Walker, 2019). Depending on the amount of video produced, this can become a prohibitive cost, especially for smaller institutions.

\section{Use of Automatic Transcription}

Automatic Speech Recognition (ASR) technologies have improved rapidly over recent years and now are almost on a par with a professional human transcriber (Fogel, 2017; Lant, 2017). Automatic Transcription Software (ATS) such as Nuance Dragon Professional Individual v15, an off-the-shelf product, promises $99 \%$ accuracy after the software is trained with the speaker's voice (Dragon Speech Recognition, 2016). However, automatically generated captions/transcripts, can sometimes fail to convey the meaning accurately due to transcription errors. For example, in a 
small study conducted by the author none of the automatic transcripts created for the topic "Property and Bonds" (in the subject discipline of Property Management) was meaningful as the word "bond" was mis-transcribed as "bones", "blondes", "bumps", and "buttons" (Liyanagunawardena, 2019). For people with hearing-impairments such inaccuracies can result in inaccessible content.

With the increasing use of multimedia in educational materials, employing automatic transcription services may be more economical and affordable to smaller institutions than paying for professional transcription services in making these contents accessible. Given the quality of ATS is sufficient, Bokhove and Downey (2018) argue that these tools can provide a first draft that can be used for transcription creation. However, unless the automatic transcription software used provides a sufficiently accurate transcript, they can be viewed as a nuisance and may even adversely affect student learning. Munteanu et al. (2006) investigated how the quality of transcripts affected user performance and the overall user experience, they tested 48 participants under four conditions: $100 \%$ accurate transcript, transcripts with 25\% WER (Word Error Rate), transcripts with 45\% WER and no transcript. They reported speech recognition accuracy linearly influenced both performance and experience of the users. Furthermore, it showed that $45 \%$ WER transcripts were unsatisfactory and that transcripts with WER of $25 \%$ or lower would be useful and usable.

This paper reports on a user experience survey at University College of Estate Management, where automatic transcription was trialled to transcribe webinar recordings.

\section{University College of Estate Management}

University College of Estate Management (UCEM) is a leading supported online learning provider for the built environment based in Reading, UK. Established in 1919, UCEM was previously known as the College of Estate Management (CEM) and was originally a postal distance education provider until 2014, when it started to offer fully online modules to students.

At UCEM, webinars are used as a synchronous learning opportunity for the distant students and on average there are about 10 webinars (each about 60 minutes) for each module with further "drop-in surgeries" (each about 15 minutes). Due to the international nature of the UCEM student body, not all students are able to join webinars synchronously as there will always be the challenge of time zone differences. Therefore, these webinars are recorded so that students can access them at a convenient time.

All UCEM created educational videos are accompanied by transcripts and or captions except for webinar recordings. Because of the volume of webinars conducted, it was not feasible to source transcriptions using the existing transcript creation workflow for all UCEM webinar recordings both due to time and cost implications. Webinar transcripts have been provided as an accessibility aid for students with hearing impairments. However, there is evidence to suggest that not just students with disabilities, but all students benefit from captions/transcripts (Linder, 2016; Gernsbacher, 2015) and UCEM wanted to offer this to all students. 
Since 2011, Elluminate was used at then CEM, which then evolved into Blackboard Collaborate. In the Spring of 2019, Zoom (https://zoom.us/) software was launched at UCEM as the webinar tool. A recorded session in Zoom shows the video side by side with the automatically generated transcript and Figure 1 shows how this is displayed to students.

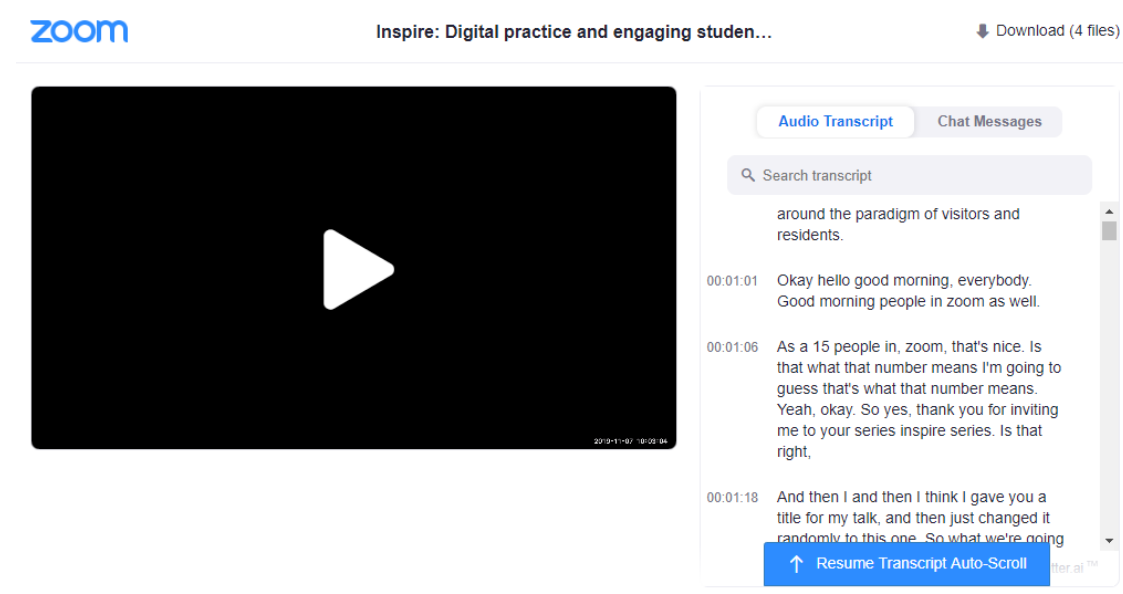

Figure 1. Zoom automatic transcript alongside the video

\section{Method}

Introduction of new learning technology software across UCEM is usually followed by an internal user feedback gathering exercise to evaluate the process, product and the user experience. The author applied for research ethics approval to use this exercise as a means to ascertain how automatic transcripts generated by the system were used, as there was wider interest in the use of automatic transcripts in the wake of UK's new accessibility regulations, "The Public Sector Bodies (Websites and Mobile Applications) (No. 2) Accessibility Regulations 2018”.

After obtaining ethical clearance through the UCEM Research Committee, two anonymous feedback surveys (student feedback survey and staff feedback survey) were conducted using the "OnlineSurveys" questionnaire administration tool, to understand user perspective of the newly deployed Zoom webinar software. This paper presents the results of the two user feedback surveys: student survey and staff survey focusing on the automatic transcription feature offered by Zoom.

- $\quad$ Student survey was open from June 10, 2019 - July 31, 2019 and attracted 283 responses

- Staff survey was open from June 25, 2019 - August 31, 2019 and attracted 27 responses

The student survey was advertised on a VLE banner and tutors were made aware of the student survey so that they could encourage students to give feedback. The UCEM marketing team also promoted the survey via social media posts. However, to participate in the survey, students had to $\log$ on to the VLE removing any possibility of outsiders contributing to the survey. The staff survey was advertised by emailing 91 academic and academic support staff who had hosted webinars using the new software.

The comments quoted in this paper are direct quotes from the surveys and may contain spelling and grammar errors. Any names or any other identifying information has been removed. 


\section{Data Analysis}

Microsoft Excel and Nvivo12 software were used to analyse the data collected. Data was coded in Nvivo using open coding practice. Thematic analysis (Braun \& Clarke, 2006) was performed to identify patterns and themes within the qualitative data collected.

\section{Results and Discussion}

\section{Student Survey}

Out of the student survey responses 282 were useable. The student survey respondents included 49\% undergraduates, $47 \%$ postgraduates and others consisting of Level 3 (equivalent to Advanced Level qualification) and foundation level students. There were more male students $(175,62.3 \%)$ responding to the survey than female students (103). At the time of the survey, the UK construction industry employed only $14 \%$ of females (Powell, 2019) and the institution's student body consisted of $29 \%$ female students. The number of female students who responded may seem low, but at $36.5 \%$ this is representative of the sector and the student body. 5.7\% of students considered themselves to have a disability while $2.5 \%$ of students did not disclose this information. Despite the active effort to reach the students registered with the disability and wellbeing service to gather their feedback, the representation of disabled students in the survey is lower than that of the UCEM student population (11\% as of September 30, 2019). Students from 36 countries responded to the survey and the majority were from the UK $(172,63 \%)$. Non-UK students represented $25 \%$ of the UCEM student body (as of September 30, 2019).

97.8\% of the students have watched at least one recorded webinar session showing the importance of recorded webinars for UCEM students. However, only 52.7\% of students (144) had used the audio transcript. 5.1\% (14) of the students were unaware of the availability of the transcript facility and $42.1 \%$ (115) students indicated that they had not used the audio transcript facility.

A follow-up question, "Did you find the transcript useful? Why?", was asked of the students who indicated that they had used transcripts. Out of the 130 students who answered this free text question, 104 students ( $80 \%$ of those who responded to this question) agreed that the transcripts were useful while $14 \%$ indicated that the transcripts were not useful. Out of the 92 respondents from non-English speaking countries (excluding respondents from majority English speaking countries), 40 responded to the free text question, “Did you find the transcript useful? Why?". Only two respondents said that the transcripts were not useful. The large majority, 95\% of students who have English as a foreign language and responded to the question, found transcripts a useful addition to understand what is being said in the webinars.

\section{Staff Survey}

There were 27 responses for the staff survey (out of about 90 who were sent the survey link) and the low number of responses made it difficult to form any firm conclusions from this survey. One response was eliminated from the survey as it was from a staff member who did not host webinars for students (as identified through the role at UCEM). Therefore, the meaningful number of responses was 26 , from 14 females, 11 males and one person who did not want to disclose gender. 
Only 13 tutors viewed the audio transcripts and 12 of them responded to the follow-up question "Did you find the transcript useful?". Only four found it useful, six found it not useful while two were indifferent.

\section{Accuracy and Usefulness of Transcripts}

The results show that students generally find the automatically generated transcripts are useful. International students find them useful to alleviate difficulties with language and or accents. The author's previous work analysing accuracy of six automatic transcription software in a built environment specific context showed Zoom software transcriptions to be on average about $73.7 \%$ accurate (Liyanagunawardena, 2019). The findings of Munteanu et al. (2006) suggested that transcripts with WER of $25 \%$ or lower would be useful and usable. Though the average accuracy of the Zoom transcripts used in this study are likely to be slightly lower than suggested by Munteanu, et al. (2006), the survey showed that the transcripts were still useful to UCEM students.

However, the same transcripts were viewed by tutors in a different and more negative light. For example, some of the responses to the open-ended question about usefulness of transcripts were:

"Only as a source of amusement! There are frequent errors and I would not find them helpful if I were using them for teaching or studying purposes."

Therefore, the qualitative data provided by the students in the open-ended question about transcripts was useful to understand why, these not so perfect, transcripts were useful (or not) to them. These comments consisted of 7 pages of text (just over 2,400 words).

In addition to the tutors, some students also found the transcripts to be unusable due to two reasons: mainly due to inaccuracies and in some instances the failure of auto-scroll functionality. Both groups, students who found transcripts to be useful and students who did not, mentioned transcript inaccuracies (32 instances).

"No, it's terrible! The wording is wrong, sometimes humorously so. Today it told me there was a $600 \%$ fatality rate on staircases. It fails to recognise many words, 'treads' today was consistently 'trades'. It's distractingly bad. If you were relying on it to understand what was being said you would be misled and learn gibberish."

Few students reported that the transcripts did not automatically scroll with the lecture. The author could not replicate this error and it could be possible that the browser in use or the quality of connectivity causing the auto-scrolling functionality to not work properly.

\section{Uses of Transcripts}

Most students who found the transcripts useful, used the transcript as a tool for finding specific information in the recording or jumping to a specific location in the video recording. Transcript as a tool for searching was indicated at least in 21 instances. 
As shown in Figure 1, Zoom allows the user to search a video. When a term is typed in and searched for, the software highlights all the instances of that term in the audio transcript. Furthermore, it takes the focus to the first occurrence of the term (to the timestamp of that closed caption) in the transcript. By searching for a term and then playing the video, the software will start the video at the timestamp of the closed caption containing the first occurrence of the search term - there by providing an effective search tool. The user also has the ability to scroll down the audio transcript, select another instance of the highlighted term in the transcript enabling them to quickly jump to the corresponding location in the video.

"So useful! Amazing. The search functionality is revolutionary. If I vaguely remember something being said in the webinar but can't quite remember where or when I used to have to watch almost the entire webinar again - and it took so long to load. Now, I just type a word and everything comes up. It's amazing. Ok, the audio transcript is not always spot on, but frankly it's amazing how much it does pick up especially with different accents and pronunciation of words and acronyms. Really love it."

Students also used transcripts as notes (at least 9 instances). A student with learning difficulties also found transcripts to be useful in this regard.

"yes, $i$ am dyslexic and found it very useful when $i$ needed to make notes and couldnt remember"

Two students, one with a hearing disability and one with Dyslexia mentioned how useful transcripts have been to them. Cross checking the students who identified themselves as having a disability, six out of seven students found the transcript to be useful (85.7\%).

Transcripts were useful to understand unfamiliar accents and words or when the speaker was talking too fast.

"It is useful because the lecturer's accent is not much familiar."

"If the webinar lead is speaking quickly, the audio transcript confirms what was said."

"It was useful at points when I was unable to decipher what the tutor was saying."

Transcripts were also useful to study on the go (for example while travelling or in a quiet environment). Many UCEM students study part-time while working full-time and having caring responsibilities making them time-poor learners. The availability of transcripts was helpful to some students to make better use of their time in transit.

"Yes, able to pause and continue when travelling without headphones!"

"It is useful as you can listen to it while in transit or waiting." 
Students also felt that transcripts helped them to catch-up if they were distracted.

"I use it to catch up if I'm distracted."

"Yes very - it helps when catching up hugely because you can process the information better somehow!"

Transcripts were also useful as an aid when the audio quality was poor and allowed the content to be accessed without the need to download large video files. While downloading a large video file may not be an issue for many people enjoying unlimited broadband access, students taking courses with UCEM from developing parts of the world may find this a challenge. Therefore, transcripts also bridged a barrier for access in terms of connectivity.

"In some instances when listening to a webinar recording, the audio would break up slightly, it was helpful to have the transcript it refer to confirm what my lecturer had said.”

"Allows options for downloading in various data sizes."

Some students preferred reading transcripts than watching a video; others wanted to visualise the discussion while some wanted to listen while reading the transcripts to follow the conversation better. Some students used transcripts as an alternative format (at least 8 instances).

"yes i find they are useful. i understand better by reading something than listening to it."

"It helps me sometimes to read along - bit like subtitles on a movie. I quite like it but I'm kinda weird like that."

"They useful because you visual follow the audio in conjunction with the chat transcript."

Transcripts were welcomed by international students too.

"As a non-native (English) speaker, it's great to understand the audio-transcript."

"as I'm not a English student, it gives more convenience to understand the speaker's explanation.”

There were others (native English students) who commented that due to poor accuracy of the transcript, it would be harder for non-native English speakers.

"No, poor quality transcription. Could confuse some students, especially those for whom English isn't their first language."

This shows the need to reach all user groups to get their views, as people in one group may interpret a situation in one way, but this may not be the way other groups will actually experience it. 
Even though students in this study reported that the transcripts were useful, they raised the issue about accuracy. In a technical discipline key words are important and transcription errors in these can make the content challenging for students relying on transcripts for accessibility purposes. In addition to students with disabilities, other students in the survey were relying on transcripts to compensate for unfamiliar accents and "decipher" what was being said in the webinar. Therefore, a student will experience problems if a technical term is inaccurately transcribed. For example refer to the instance mentioned above, of "Property and Bonds", where the word "bond" was inaccurately transcribed by all automatic transcription software that was tested (Liyanagunawardena, 2019).

Dealing with transcription inaccuracies will be a necessity when employing automatic transcription technologies. There could be quick checks by the webinar host to ascertain the accuracy of the transcript and a system in place for students to report inaccuracies. However, both these require staff time to address transcription inaccuracies. An alternative approach is taken by Synote (https://synote.com) software system where they provide a facility for the student community to correct any transcription errors. However, for this to work all students require accounts and if the software licensing is based on the number of users (here the number of students) it could again increase the cost of transcription.

This small study shows that students use transcripts in multiple ways: finding specific information in the recording or skipping to a specific location in the video recording; as notes; as accessibility aid; to understand unfamiliar accents and words (technical terms); when the speaker was talking too fast; to study on the go; catch-up if distracted; compensating for poor audio and/or connectivity; for those who prefer reading than listening to audio and as an aid for non-native English speakers.

The findings of this study are corroborated by previous studies (Linder, 2016). Linder (2016) provided specific answer options to choose from in the survey together with the opportunity to give open ended responses. These were categorised under five umbrella themes: environmental; poor video/audio quality and/or instructor difficult to understand; convenience; disability accommodation; and as a learning aid. In the present study, which only provided open response options, students identified almost identical advantages of transcripts. It is not clear whether the students in the former study had used transcripts to overcome difficulties of large file downloads. It is possible that the students coming from the US did not have this difficulty whereas for UCEM's international students this was another barrier to overcome.

\section{Limitations}

The study did not attract sufficient responses from the tutor community to make meaningful comparison of the use of transcripts between the two groups tutors and students. The study relied on anonymous self-directed surveys as the only data source; therefore, is inherent with the limitations of this data collection method.

The study reported student responses to UCEM's first implementation of automatic transcription to webinar recordings. There could be an element of "novelty factor" affecting the student 
responses as this was the first instance many of them had seen transcripts accompanying webinar recordings (previously transcripts for webinar recordings were only provided as an accommodation on modules where deaf students were registered).

Despite publicising the survey via the Disability and Wellbeing Service at UCEM, the study did not attract sufficient responses from students with disabilities (especially students who have hearing impairments) to understand whether the less than perfect transcript was a help or hindrance to them.

\section{Conclusion}

The study found that many students appreciated the availability of automatic transcripts despite their less than perfect accuracy level. Non-native English speakers and students who declared disabilities also indicated that they benefited from the availability of automatic transcripts. Students used transcripts mainly as a tool for searching (within) a video. This small study shows that students used transcripts in multiple ways: finding specific information or skipping to a specific location in the video; as notes; as accessibility aid; to understand unfamiliar accents and words (technical terms); to understand a fast speaker; to study on the go; to catch-up if distracted; compensating for poor audio and/or connectivity; for those who prefer alternative formats and as an aid for non-native English speakers.

\section{References}

1. Association for Learning Technology. (2019). Reporting from the Annual Survey 2018. Retrieved October 11, 2019, from https://repository.alt.ac.uk/2431/2/ReportingfromtheAnnualSurvey2018.pdf

2. Braun, V., \& Clarke, V. (2006). Using thematic analysis in psychology. Qualitative Research in Psychology, 3(2), 77-101.

3. Fogel, S. (2017, October 3). IBM inches toward human-like accuracy for speech recognition. Engadget [Blog post]. Retrieved from https://www.engadget.com/2017/03/10/ibmspeechrecognition-accuracy-record/

4. Gernsbacher, M. A. (2015). Video Captions Benefit Everyone. Policy Insights Behavioral and Brain Sciences, 2(1), 195-202. doi:10.1177/2372732215602130

5. Kaltura. (2019). Sixth Annual State of Video in Education 2019: Insights and trends. Rerieved from https://corp.kaltura.com/wpcontent/uploads/2019/07/The_State_of_Video_in_Education_2019-1.pdf

6. Lant, K. (2017, August 23). Microsoft's Speech Recognition is now as Good as a Human Transcriber. Futurism the Byte [Blog post]. Retrieved from https://futurism.com/microsoftsspeech-recognition-is-now-as-good-as-a-humantranscriber

7. Linder, K. (2016). Student uses and perceptions of closed captions and transcripts: Results from a national study. Corvallis, OR: Oregon State University. Retrieved from 
http://info.3playmedia.com/rs/744-UDO-697/images/Student-Survey-Report-10-25-16Final.pdf

8. Liyanagunawardena, T. R. (2019). Automatic Transcription Software: Good Enough for Accessibility? A Case Study from Built Environment Education. In A. Volungeviciene, \& A. Szűcs (Eds.), EDEN 2019 Annual Conference: Connecting through Educational Technology to produce effective learning environments (pp. 378-386). Budapest, Hungary: European Distance and ELearning Network.

9. Munteanu, C., Baecker, R., Penn, G., Toms, E., \& James, D. (2006). The Effect of Speech Recognition Accuracy Rates on the Usefulness and Usability of Webcast Achieves. Proceedings of the SIGCHI Conference on Human Factors in Computing Systems, Montreal, Canada, 493-502. doi:10.1145/1124772.1124848

10. Powell, A. (2019). Women and the Economy, Briefing Paper. Number CBP06838, 8 March 2019. House of Commons Library. Retrieved from https://researchbriefings.files.parliament.uk/documents/SN06838/SN06838.pdf

11. Walker, R. (2019). JISC Accessibility Clinic [Webinar]. Retrieved October 2, 2019, from https://jisc.adobeconnect.com/p39zrwbnj0tu/

\section{Acknowledgement}

I would like to thank Graham North and Dr Peter Stone for supporting this research work and their comments on an earlier version of the paper; Dr Adrian Shell for proofreading the article and Eliza White and Mag. Regine Klimpfinger for their help with translating the article abstract. 


\section{Appendix: Student Questionnaire}

Zoom webinar software has been rolled out at UCEM as of Spring 2019 semester. This anonymous survey is to capture user feedback with the aim to understand and analyse UCEM's transition to the new webinar software and its impact on students and staff.

The anonymous data collected will be securely stored and processed according to UCEM data protection policy.

Data used for any publication resulting from this research will be anonymised.

Participation in the research is completely voluntary and the participants are at liberty to withdraw at any time without prejudice or negative consequences

Dr. Tharindu Liyanagunawardena can be contacted at tharindu@ucem.ac.uk for any further queries regarding the research project

In the event of any concern regarding the research ethics relating to this project please contact the Director - Research, Innovation and Partnerships.

Details about you:

1. Which level are you studying at UCEM? (Level 3, Foundation, Undergraduate, Postgraduate, Other - please specify)

2. What is your gender? (male, female, other, prefer not to say)

3. What is your age? (Under 18, 19-24, 25-34, 35-44, 45-54, 55-64, 65 and older)

4. Do you consider yourself to have a disability? (yes, no, prefer not to say)

5. What is your country of domicile?

Your views about Zoom webinar software tool:

6. How did you access/where did you find the guidance information using Zoom? (select all that applies) (Module page, My community area in the Student Hub, VLE banner, I did not use guidance information, other - please specify)

7. Indicate your response to each of these statements about the Zoom webinar tool and the information/guidance you received about Zoom (strongly agree to disagree with option for not applicable)

a. I was informed about the Zoom roll-out and its progress via VLE banners

b. I found the Zoom guidance videos useful

c. I found the Zoom guidance blog posts useful 
d. Overall, I found the Zoom guidance which was provided useful

8. Have you joined at least one live Zoom webinar session? (Yes/No)

a. Why?

b. I was able to join Zoom sessions with ease (strongly agree to strongly disagree with option for not applicable)

9. Have you watched at least one recorded Zoom webinar session? (yes, no)

a. Why?

b. Zoom provides good quality audio and video (strongly disagree to strongly agree with option for not applicable)

c. Have you used the Chat transcript? (yes, no, I wasn't aware of Chat transcript being available)

d. Have you used the audio transcript? (yes, no, I wasn't aware of transcript being available)

e. Di you find the transcript useful? Why?

10. Have you been a UCEM student previously and participated in Blackboard Collaborate webinar sessions with UCEM? (yes, no)

a. In comparison to your previous Blackboard Collaborate experience which do you prefer? (previous - Blackboard Collaborate webinar tool, New - Zoom webinar tool)

b. Why?

11. Please provide any other feedback regarding the use of Zoom webinar tool at UCEM?

Your webinar experience:

12. Ideally what purpose do you believe a webinar should achieve for your learning?

13. Stat at least one thing you like and one thing you dislike regarding webinars?

14. Do you like seeing your tutor on camera? (yes, no)

a. Why?

15. Do you find it useful having your facilitator at the webinar? (yes, no)

a. Why? 
16. Please indicate whether you liked, disliked or have never used the following functions within your webinars (answer options: like, dislike, not used)
a. Hand Up
b. Yes
c. No
d. Go Slower
e. Go Faster
f. Thumbs Up
g. Thumbs Down
h. Clapping
i. Chat Box
j. Microphone
k. Webcam
1. Polls
m. Looking at live VLE pages

17. Is there anything else you would like to let us know about your webinar experience? 